\title{
Detection of Fusarium oxysporum f. sp. cubense tropical race 4 strain in northern Queensland
}

\author{
W. T. O'Neill ${ }^{1}$ - J. Henderson ${ }^{2}$ • J. A. Pattemore ${ }^{1}$ - C. O'Dwyer ${ }^{2} \cdot$ S. Perry ${ }^{1}$ • \\ D. R. Beasley ${ }^{1}$ - Y. P. Tan ${ }^{1}$ - A. L. Smyth ${ }^{1}$ - C. H. Goosem ${ }^{1}$ - K. M. Thomson ${ }^{1}$. \\ R. L. Hobbs ${ }^{1}$ - K. R. E. Grice ${ }^{3}$ - P. Trevorrow ${ }^{3}$ - L. L. Vawdrey ${ }^{4}$. \\ N. Pathania ${ }^{3}$ - R. G. Shivas ${ }^{1}$
}

Received: 31 July 2016 / Accepted: 13 October 2016/Published online: 5 November 2016

(C) Australasian Plant Pathology Society Inc. 2016

\begin{abstract}
Fusarium oxysporum f. sp. cubense tropical race 4 (TR4) is reported for the first time in northern Queensland, the centre of Australia's commercial banana production. The identity of the pathogen was confirmed by vegetative compatibility group testing, TR4 specific PCR tests and sequencing. Although presently confined to a single property, the disease poses a serious threat to Australia's banana industry.
\end{abstract}

Keywords Fusarium oxysporum f. sp. cubense · Panama disease $\cdot$ Banana $\cdot$ Queensland

Panama disease of banana, caused by the soil-borne fungus Fusarium oxysporum f. sp. cubense (Foc), is a major constraint to the production of susceptible cultivars in infested areas worldwide (Ploetz 2015). Vegetative compatibility group (VCG) 01213/16 of Foc, also known as tropical race 4 (TR4), is highly virulent on Cavendish cultivars (Musa AAA) in tropical latitudes. In Australia, this strain was first detected in the Northern Territory (near Darwin) in 1997 (Conde and Pitkethley 2001).

W. T. O’Neill

wayne.o'neill@daf.qld.gov.au

1 Biosecurity Queensland, Department of Agriculture and Fisheries, Ecosciences Precinct, Dutton Park, QLD 4102, Australia

2 Centre for Plant Science, Queensland Alliance for Agriculture and Food Innovation, Ecosciences Precinct, The University of Queensland, Dutton Park, QLD 4102, Australia

3 Department of Agriculture and Fisheries, Agri-science Queensland, 28 Peters Street, Mareeba, QLD 4880, Australia

4 Department of Agriculture and Fisheries, Agri-science Queensland, 24 Experimental Station Road, South Johnstone, QLD 4859, Australia
Since its discovery, banana production has declined dramatically in the Northern Territory and the number of commercial farms has fallen by over $90 \%$, with limited future prospects in the absence of resistant varieties (Cook et al. 2015).

Northern Queensland currently accounts for more than $90 \%$ of Australian banana production (http://abgc.org. au/banana-industry-2/our-industry/key-facts/), which is largely based on Cavendish cultivars. Since the majority of the banana industry is located in a confined geographic area on the coast between latitudes $15-18^{\circ} \mathrm{S}$, it is highly vulnerable to impacts of natural disasters (especially tropical cyclones, see Lindsay 2016) and disease epidemics. In mid-February 2015, stem and corm samples were taken from two Cavendish plants (cv. Williams) in the Tully region of northern Queensland. These plants exhibited symptoms (leaf yellowing and necrosis) consistent with bacterial rhizome rot. Bacterial rhizome rot is a common disease of mature banana plants in Australia's wet tropics during periods of hot, wet weather, typically peaking from January to April (Akiew et al. 2002). Internal examination of the plants revealed water-soaked bacterial lesions interspersed with some vascular streaking. Fusarium oxysporum was consistently isolated from the discoloured vascular strands, as were Enterobacteriaceae softrot bacteria. Subsequent samples taken a few weeks later from adjacent plants had more typical external and internal symptoms of Panama disease (leaf yellowing and wilt, widespread, continuous vascular streaking) with less bacterial rot (Figs. 1 and 2).

VCG and molecular analysis of monoconidial cultures of the $F$. oxysporum isolates recovered from the samples confirmed the presence of TR4. VCG analysis was carried out according to the technique developed by Cove (1976) and modified by Puhalla (1985). Nitrate non-utilising (nit) mutants were produced from the diagnostic isolates on potato sucrose 


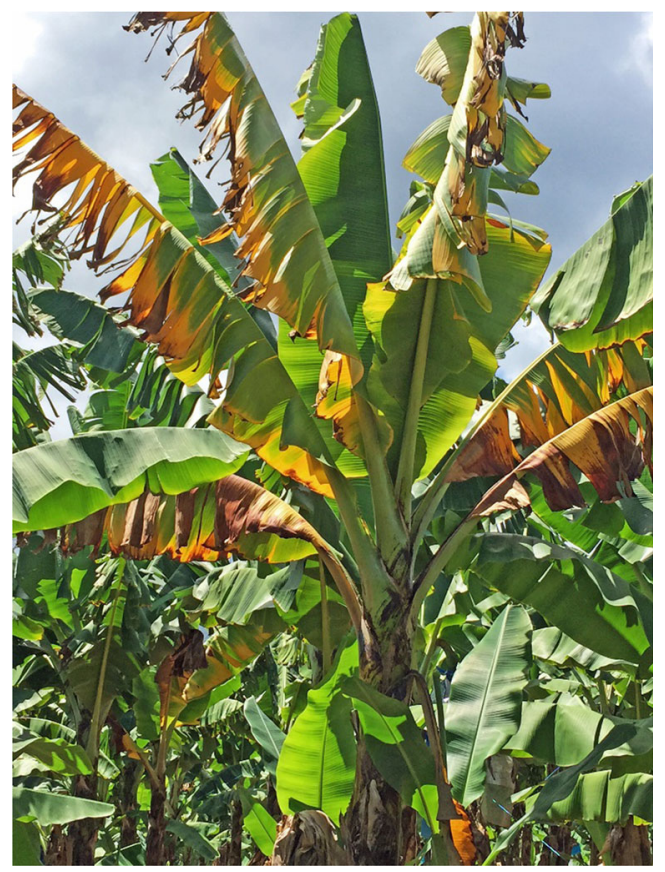

Fig. 1 Foliar yellowing of a Cavendish banana (cv. Williams) infected with Panama disease TR4 at the site where the first detection in Queensland occurred

medium amended with $1.5 \%$ potassium chlorate (KPS medium) and paired with tester Nit M mutants obtained from the culture collection of the Queensland Plant Pathology Herbarium (BRIP). VCG 01213/16 Nit M testers used for confirmatory testing had been derived from isolates collected from previously diagnosed TR4 outbreaks in Indonesia (BRIP 58649) and Malaysia (BRIP 58734, BRIP 62807). The nit mutants from the diagnostic isolates anastomosed to form stable heterokaryons when paired with the TR4 Nit M testers on minimal media, thus confirming their identity as VCG 01213/ 16 (Fig. 3). To date, 29 representative TR4 cultures from the incursion have been stored at $-80{ }^{\circ} \mathrm{C}$ in $15 \%$ glycerol and accessioned as BRIP 62280, 62307-62311, 62347-62353, 62831, 63122, 64080-64081, 64112-64116, 64253-64254, 64425-64426, 64646 and 64854-64855.

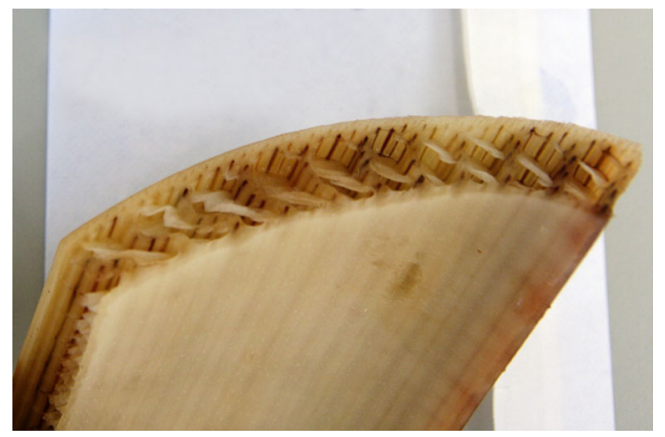

Fig. 2 Vascular discolouration of a leaf base of a Cavendish banana (cv. Williams) infected with Panama disease collected at the initial Queensland disease focus

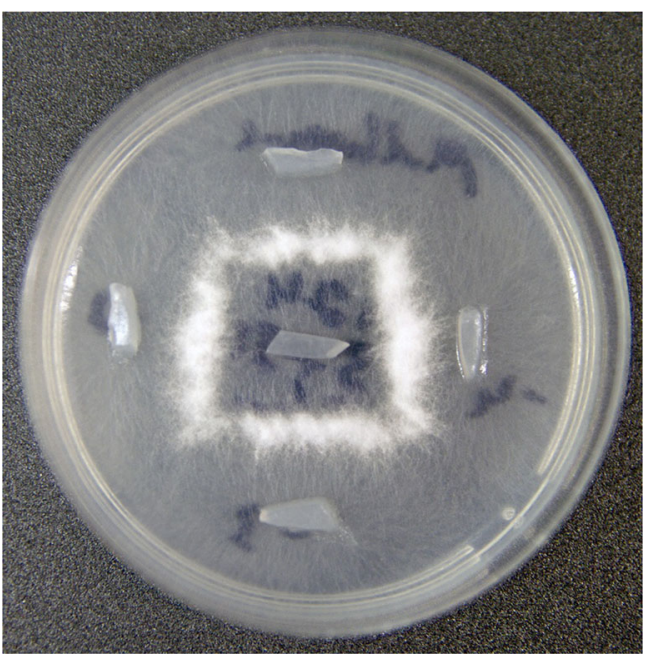

Fig. 3 Positive VCG pairing showing heterokaryon formation in lines where growth of four nit mutants (nit 1 or 3 ) derived from the diagnostic sample (placed near periphery of plate) has intersected with growth from Nit M tester (centre of plate)

DNA was extracted from monoconidial cultures using a DNeasy Plant Mini kit (Qiagen), as per the manufacturer's instructions. The DNA was used as template in three PCRs for the specific detection of TR4 (Bentley et al. 2001; Dita et al. 2010; Dita et al. 2011; Fraser-Smith et al. 2014). Primer sequences for Bentley et al. (2001) are TR4-F2 5'CAG GCC AGA GTG AAG GGG GAT3' and TR4-R1 5'CGC CAG GAC TGC CTC GTG A3'. Each sample was positive for TR4 in all three TR4-specific PCRs. The intergenic spacer region (IGS) of the ribosomal DNA (rDNA) was also sequenced to confirm the PCR result. Primers CNS1 and CNL12 (Appel and Gordon 1996) were used to amplify the region and generate flanking sequences. $F o c$-specific primers were used for internal sequencing: SFOC6F (F2) 5 'TGG TTT GGC TGG TGA GAT G3'; SFOC2R (R2) 5'CCT GTA CCT ACC ACA CAC C3'; SFOC0120E5R (R3) 5'TCC ATC TCA CCA GCC AAA C3'. The DNA sequence reads were manually checked for quality and assembled in Geneious v7.0. Contigs were aligned to IGS sequences from Foc VCGs, including VCG 01213/16 (Genbank FJ985328), which has a unique IGS sequence. The IGS sequences of the samples had $100 \%$ homology to the TR4 reference sequence and were confirmed as TR4. IGS sequences from BRIP 62347 and BRIP 62353 were deposited as Genbank KX101210 and KX101211, respectively. An extensive process of validation and/or verification of existing diagnostic assays was undertaken as part of the response to the TR4 incursion. Improved molecular diagnostic protocols have been developed and are currently undergoing assessment.

Confirmation of TR4 in Queensland triggered a biosecurity response that established a containment and quarantine regime on the infested property as well as the adoption of on-farm biosecurity practices by the industry as a whole. In the 
18 months since its detection, TR4 has only been detected on the property where it was originally found. However, as a result of an intensive surveillance program it is now known to occur at several locations on that property. The Biosecurity Queensland surveillance program has completed inspections of over 250 individual properties; including residential, feral and commercial banana plantings. A program of repeat surveillance is in place on commercial banana farms that have an identified link to the infested property. To date over 800 survey events have been completed (covering approximately $80 \%$ of the northern Queensland production area) resulting in the collection and analysis of more than 1400 diagnostic samples. The source and pathway for the introduction of TR4 into northern Queensland has not been identified despite intensive investigation. In addition to the surveillance program, the banana industry and Queensland government have made significant investment in research projects investigating sources of resistance, developing resilient production systems and improving biosecurity tools (including an improved clean planting material scheme) to prepare for a sustainable banana industry in the face of TR4.

\section{References}

Akiew S, Arthy J, Vawdrey L, Lindsay S (2002) Epidemiology and control of banana corm rot. Final Report to Horticulture Australia Ltd Project FR98040 p 19

Appel DJ, Gordon TR (1996) Relationships among pathogenic and nonpathogenic isolates of Fusarium oxysporum based on the partial sequence of the intergenic spacer region of the ribosomal DNA. Mol Plant Microbe In 9(2):125-138

Bentley S, Moore NY, Pattemore J (2001) Fusarium wilt diagnostics laboratory manual. CRC for Tropical Plant Protection, Brisbane

Conde BD and Pitkethley RN, 2001 The discovery, identification and management of banana Fusarium wilt outbreaks in the Northern Territory of Australia. In: Molina AB, Nik Masdek NH, Liew KW (eds) Banana Fusarium wilt management: towards sustainable cultivation. Proceedings of the International workshop on the banana Fusarium wilt disease, Genting Highlands Resort, Malaysia, 18-20 October 1999. INIBAP, Montpellier. p 260-265

Cook DC, Taylor AS, Meldrum RA, Drenth A (2015) Potential economic impact of Panama disease (tropical race 4$)$ on the Australian banana industry. J Plant Dis Protect 122(5-6):229-237

Cove DJ (1976) Chlorate toxicity in Aspergillus nidulans: the selection and characterisation of chlorate resistant mutants. Heredity 36:191-203

Dita MA, Waalwijk C, Buddenhagen IW, Souza MT Jr, Kema GH (2010) A molecular diagnostic for tropical race 4 of the banana fusarium wilt pathogen. Plant Pathol 59:348-357

Dita MA, Waalwijk C, Buddenhagen IW, Souza MT Jr, Kema GHJ (2011) Corrigendum. Plant Pathol 60:384

Fraser-Smith S, Czislowski E, Meldrum RA, Zander M, O'Neill W, Balali GR, Aitken EAB (2014) Sequence variation in the putative effector gene SIX8 facilitates molecular differentiation of Fusarium oxysporum f.sp. cubense. Plant Pathol 63: $1044-1052$

Lindsay S (2016) Farm practices to manage the impact of severe tropical cyclone damage on banana production - a case study from tropical Australia. Acta Hortic 1114:275-284. doi:10.17660/ActaHortic.2016.1114.37

Ploetz RC (2015) Fusarium wilt of banana. Phytopathology 105(12): 1512-1521. doi:10.1094/PHYTO-04-15-0101-RVW

Puhalla JE (1985) Classification of strains of Fusarium oxysporum on the basis of vegetative compatibility. Can J Bot 63:179-183 